\title{
Serum follicle-stimulating hormone level is associated with human epidermal growth factor receptor type 2 and Ki67 expression in post-menopausal females with breast cancer
}

\author{
JUN ZHOU ${ }^{1,2}$, YIDING CHEN ${ }^{2}$, YITING HUANG $^{3}$, JINPEI LONG $^{2}$, FANG WAN $^{2}$ and SUZHAN ZHANG ${ }^{1}$ \\ ${ }^{1}$ Key Laboratory of Cancer Prevention and Intervention, China National Ministry of Education, \\ Key Laboratory of Molecular Biology in Medical Sciences of Zhejiang, Cancer Institute of Zhejiang University, Hangzhou, \\ Zhejiang 310009; ${ }^{2}$ Department of Surgery, The Women's Hospital of Zhejiang University, Hangzhou, Zhejiang 310006; \\ ${ }^{3}$ Department of Pathology and Pathophysiology, School of Zhejiang University, Hangzhou 310012, P.R. China
}

Received February 16, 2013; Accepted July 25, 2013

DOI: $10.3892 / \mathrm{ol} .2013 .1516$

\begin{abstract}
The present study aimed to determine the association between levels of the gender hormones, follicle-stimulating hormone (FSH), luteinizing hormone $(\mathrm{LH})$, progesterone $(\mathrm{P})$ and prolactin (PRL), and two breast cancer molecular markers, human epidermal grow th factor receptor 2 (Her-2) and $\mathrm{Ki67}$, in post-menopausal patients with breast cancer. A retrospective study of the serum hormone levels of FSH, LH, P and PRL and the expression status of Her-2 and Ki67 was performed using 187 post-menopausal females with breast cancer. Her- $2^{+}$breast cancer patients exhibited higher serum FSH levels compared with Her-2 patients $(69.47 \pm 3.219$ vs. $58.56 \pm 1.516 \mathrm{IU} / \mathrm{l})$. The patients with high Ki67 expression [immunohistochemistry (IHC), 3+] displayed higher FSH $(72.51 \pm 4.616$ vs. $60.53 \pm 1.476 \mathrm{IU} / \mathrm{l})$ and LH (32.33 \pm 1.916 vs. $26.98 \pm 0.8852$ IU/1) levels than those with lower Ki67 expression. No correlation was identified between the FSH, LH, P and PRL hormone levels, tumor stages and lymphovascular invasion (LVI). In conclusion, a higher serum FSH level was identified in Her- $2^{+}$post-menopausal patients with breast cancer. Higher serum FSH and LH levels were also observed in breast cancer patients with high Ki67 expression. FSH and LH may function in the progression of breast cancer.
\end{abstract}

Correspondence to: Professor Suzhan Zhang, Key Laboratory of Cancer Prevention and Intervention, China National Ministry of Education, Key Laboratory of Molecular Biology in Medical Sciences of Zhejiang, Cancer Institute of Zhejiang University, 88 Jiefang Road, Hangzhou, Zhejiang 310009, P.R. China

E-mail: zrsj@zju.edu.cn

Key words: breast cancer, human epidermal growth factor receptor 2, Ki67, follicle-stimulating hormone, post-menopausal

\section{Introduction}

Breast cancer is one of the most common cancers in females and one of the main causes of cancer-related mortality worldwide (1). In China, the incidence and mortality rates of breast cancer have continuously increased $(2,3)$. Chinese patients with breast cancer exhibit a more invasive ductal carcinoma with larger tumor sizes and higher human epidermal growth factor receptor 2 (Her-2) overexpression than patients from the West (4).

Her-2 regulates cell growth, survival and differentiation via interlinked signal transduction. Her-2 amplification and overexpression have been reported in $15-30 \%$ of all breast cancer cases and are associated with a poorer prognosis and more aggressive clinical manifestations $(5,6)$. The exact mechanism of Her-2 overexpression remains unclear.

The nuclear-associated antigen Ki67 protein may be detected in the active phases of the cell cycle in late $G_{1}, S$, $\mathrm{G}_{2}$ and $\mathrm{M}$ phases, but not in the resting phase (7). The overexpression of $\mathrm{Ki} 67$ corresponds to the high proliferation rate of tumor cells. Ki67 is used as the main marker to distinguish between luminal A $(\mathrm{Ki} 67<14 \%)$ and luminal B $(\mathrm{Ki} 67 \geq 14 \%)$ breast cancers. Luminal B indicates that the tumor is more aggressive and requires chemotherapy (8).

Studies have identified that hormones other than estradiol (E2) may be associated with an increased risk of breast cancer. High serum prolactin (PRL) levels have been reported in pre-menopausal females with breast cancer (9) and circulating PRL levels are positively correlated with the risk of breast cancer (10). Although gene scans have shown that the expression of luteinizing hormone/choriogonadotropin receptor (LH/CGR) in breast cancer is either undetectable or very low (11), studies have identified that LHCGR may be detected in breast cancer cells (12-14) and that LH participates in the tumor progression of breast cancer using LHCGR. Nearly $40 \%$ of patients with breast cancer exhibit an increased human chorionic gonadotropin (hCG)-immunoreactivity in the serum $(15,16)$. However, few studies have focused on the association between follicle-stimulating hormone (FSH) and breast cancer. 
FSH stimulates follicle growth and development in the ovaries and produces the maximum amount of mature spermatozoa in the testes. FSH and its corresponding receptor (FSHR) have an important function in various cancers, including prostate (17), endometrial (18) and ovarian (19) cancer. FSH-FSHR induces cancer cell proliferation, differentiation and metastasis by activating adenylyl cyclase, thereby resulting in increased cAMP levels $(20,21)$. The overexpression of FSHR may be associated with Her-2 overexpression in ovarian cancer (22). Although FSHR expression has not been identified in primary tissues of breast cancer (23), high FSH levels have been associated with a significantly poor prognosis in patients with premenopausal breast cancer (24). FSH has also been linked to breast cancer cell proliferation and an increased risk of breast cancer development in females who have undergone infertility treatments (25). However, few studies have focused on the association between the serum level of FSH and the expression status of Her-2 and Ki67.

The present study hypothesized that gonadotropic hormone has a function in the proliferation of breast cancer cells. The association between serum hormonal levels and the expression status of two relative breast cancer proliferation molecular markers, Her-2 and Ki67, was retrospectively analyzed in 187 post-menopausal females with breast cancer.

\section{Materials and methods}

Patients. The data of 187 post-menopausal breast cancer patients were collected from The Women's Hospital of Zhejiang University (Zhejiang, China) between January 2007 and October 2012. The post-menopausal standard was based on the National Comprehensive Cancer Network Guidelines of 2012. The serum hormonal levels of FSH, $\mathrm{LH}$, progesterone (P) and PRL were evaluated at the initial admission of the patients. The patients who were administered chemotherapy, radiotherapy or hormonal replacement therapy prior to the surgery were excluded, as the therapies may have affected their hormonal levels. The study was approved by The Women's Hospital of Zhejiang University Ethics Committee. Written informed consent was obtained from the patients.

Determination of circulating levels of FSH, LH, $P$ and $P R L$. Venous blood was collected in 6-ml ethylenediaminetetraacetic acid (EDTA) tubes at 6 a.m. and analyzed within $24 \mathrm{~h}$. The circulating hormone levels, including those of FSH, LH, P and PRL, were measured using enzyme immunoassays (Roche Diagnostics, Mannheim, Germany) on an E170 module.

Evaluation of Her-2 and Ki67 by immunohistochemistry(IHC). The tumor grades were assessed using the tumor-node-metastasis (TNM) staging system. The slides were re-examined by two expert pathologists to confirm the tumor type, size and grade and the presence of lymphovascular invasion (LVI). The classification of Ki67 was determined based on two methods. The first method divided patients into two groups based on the positive rates of $<14 \%$ (IHC, 0 or $1+$ ) or $\geq 14 \%$ (IHC, $2+$ or $3+$ ). The second method divided patients based on the IHC results of $3+$ as group 1 and $2+/ 1+/-$ as group 2 .
Table I. Clinical and pathological features of patients $(n=187)$.

\begin{tabular}{|c|c|}
\hline Features & Value \\
\hline \multicolumn{2}{|l|}{ Age, years } \\
\hline Median & 62 \\
\hline Range & $47-83$ \\
\hline \multicolumn{2}{|l|}{ FSH, IU/1 } \\
\hline Mean & 61.83 \\
\hline Range & $8.82-149.6$ \\
\hline \multicolumn{2}{|l|}{ LH, IU/1 } \\
\hline Mean & 27.73 \\
\hline Range & $0.1-77.92$ \\
\hline \multicolumn{2}{|l|}{$\mathrm{P}, \mathrm{mmol} / \mathrm{l}$} \\
\hline Mean & 0.673 \\
\hline Range & $0.05-2.84$ \\
\hline \multicolumn{2}{|l|}{ PRL, ng/ml } \\
\hline Mean & 11.38 \\
\hline Range & $0.975-61$ \\
\hline \multicolumn{2}{|c|}{ Her-2, n (\%) } \\
\hline Positive & $56(29.9)$ \\
\hline Negative & $131(70.1)$ \\
\hline \multicolumn{2}{|c|}{$\mathrm{Ki67,n}(\%)$} \\
\hline \multicolumn{2}{|l|}{ Method 1} \\
\hline$<14 \%$ & $89(47.6)$ \\
\hline$\geq 14 \%$ & $98(52.4)$ \\
\hline \multicolumn{2}{|l|}{ Method 2} \\
\hline negative & $14(7.5)$ \\
\hline $1+$ & $75(40.1)$ \\
\hline $2+$ & $61(32.6)$ \\
\hline $3+$ & $37(19.8)$ \\
\hline \multicolumn{2}{|l|}{ LVI, n (\%) } \\
\hline Negative & $111(59.4)$ \\
\hline$\leq 3$ & 39 (20.9) \\
\hline $4-9$ & $26(13.9)$ \\
\hline$\geq 10$ & $11(5.9)$ \\
\hline \multicolumn{2}{|c|}{ Tumor stage, n (\%) } \\
\hline 0 & $13(7.0)$ \\
\hline I & $25(13.4)$ \\
\hline $\mathrm{IIa} / \mathrm{IIb}$ & $76(40.6) / 31(16.6)$ \\
\hline $\mathrm{IIIa} / \mathrm{IIIb}$ & $25(13.4) / 15(8.0)$ \\
\hline IV & $2(1.1)$ \\
\hline
\end{tabular}

FSH, follicle-stimulating hormone; LH, luteinizing hormone; P, progesterone; PRL, prolactin; Her-2, human epidermal growth factor receptor type 2; LVI, lymphovascular invasion.

Statistical analysis. The statistical analysis was performed using SPSS 19.0 software (SPSS, Inc., Chicago, IL, USA). A Mann-Whitney U test was performed to determine the association between the hormonal levels and the expression rates of Her-2 and Ki67. A one-way ANOVA was performed to evaluate the association between the hormonal level, LVI and the tumor 
Table II. Correlation between the serum hormonal levels of FSH, LH, P and PRL, tumor status and LVI in post-menopausal patients with breast cancer.

\begin{tabular}{|c|c|c|c|c|c|c|c|c|c|}
\hline \multirow[b]{2}{*}{ Hormone } & \multicolumn{5}{|c|}{ Tumor stage } & \multicolumn{4}{|c|}{ LVI } \\
\hline & 0 & I & $\mathrm{IIa} / \mathrm{IIb}$ & IIIa/IIIb & IV & 0 & $\leq 3$ & 4-9 & $\geq 10$ \\
\hline FSH & & 0.909 & 1.000 & 0.979 & 0.424 & & 0.976 & 0.730 & 0.999 \\
\hline LH & & 1.000 & 0.624 & 0.817 & 0.839 & & 0.646 & 0.997 & 0.994 \\
\hline $\mathrm{P}$ & & 0.377 & 0.286 & 0.282 & 0.530 & & 1.000 & 0.561 & 0.988 \\
\hline PRL & & 0.670 & 1.000 & 0.959 & 0.919 & & 0.995 & 0.555 & 0.979 \\
\hline
\end{tabular}

FSH, follicle-stimulating hormone; LH, luteinizing hormone; P, progesterone; PRL, prolactin; LVI, lymphovascular invasion. Data are represented as P-values relative to Stage 0 and LVI stage 0 .

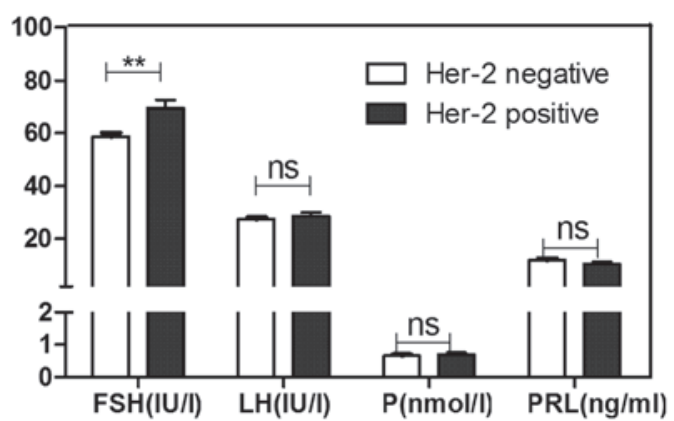

Figure 1. Circulating levels of hormones in Her-2+ and Her-2- post-menopausal females with breast cancer. Data are presented as the mean \pm SEM; $\mathrm{n}=56$ and $\mathrm{n}=131$ as positive and negative, respectively; ${ }^{* *} \mathrm{P}<0.01 . \mathrm{FSH}$, follicle-stimulating hormone; LH, luteinizing hormone; P, progesterone; PRL, prolactin; Her-2, human epidermal growth factor receptor type 2; ns, not significant.

A

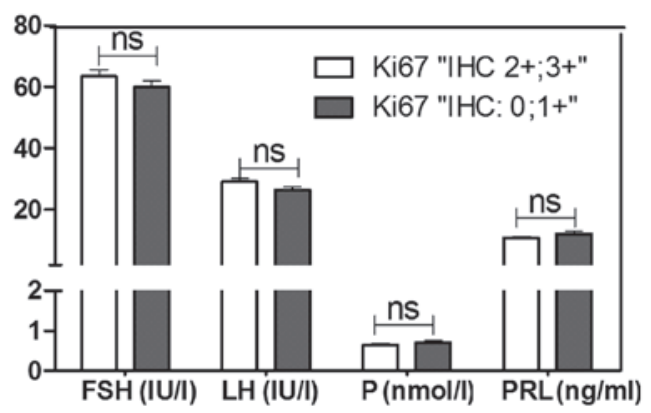

B

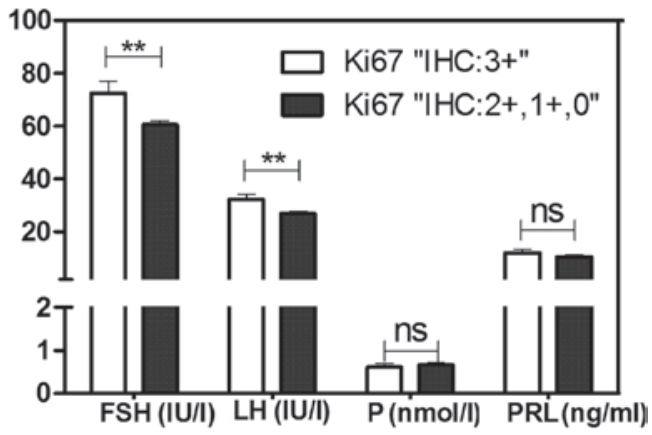

Figure 2. Circulating levels of hormones grouped by Ki67 levels in post-menopausal females with breast cancer. (A) Levels are grouped according to the IHC results, $0 ; 1^{+}$and $2^{+} ; 3^{+}\left(\mathrm{n}=89\right.$ and $\left.98 ;{ }^{* *} \mathrm{P}<0.01\right)$. (B) Levels are grouped according to the $\mathrm{IHC}$ results, 0 and $1^{+} ; 2^{+}$and $3^{+}(\mathrm{n}=150$ and $\mathrm{n}=37$, repectively; $\left.{ }^{* *} \mathrm{P}<0.01\right)$. Data are presented as mean \pm SEM. IHC, immunohistochemistry; FSH, follicle-stimulating hormone; LH, luteinizing hormone; P, progesterone; PRL, prolactin; ns, not significant. stage. All of the reported P-values were two-sided. $\mathrm{P}<0.05$ was considered to indicate a statistically significant difference.

\section{Results}

The clinical and pathological features of the 187 post-menopausal patients with breast cancer are summarized in Table I. All 187 patients underwent breast cancer surgery without previous chemotherapy, radiotherapy or any other hormonal replacement therapy. All patients were pathologically diagnosed with breast cancer.

The FSH level was strongly associated with the Her-2 status ( $\mathrm{P}=0.004 ;$ Fig. 1).TheHer-2 ${ }^{+}$patients exhibited higher FSHlevels than the Her-2 patients $(69.47 \pm 3.219$ vs. $58.56 \pm 1.516 \mathrm{IU} / \mathrm{l})$. In contrast, the LH, P and PRL hormone levels were not exhibited with significant differences between the Her-2 ${ }^{+}$and Her-2 patients with post-menopausal breast cancer.

A cut-off point of $14 \%$ was selected for Ki67. The results revealed that FSH, LH, P and PRL were not significantly different between the two groups (Fig. 2A). In contrast, group 1 exhibited higher FSH $(72.51 \pm 4.616$ vs. $60.53 \pm 1.476)$ and $\mathrm{LH}$ (32.33 \pm 1.916 vs. $26.98 \pm 0.885$ ) levels than group 2 (Fig. 2B).

The FSH, LH, P and PRL levels did not change significantly in tumor stage groups I-IV compared with stage 0 (Table II). The serum levels of the hormones were evaluated between the various LVI stage groups, however, no significant difference was identified in the circulating FSH, LH, P and PRL levels in the high LVI groups compared with the LVI-negative group.

\section{Discussion}

The effect of hormones on tumorigenesis and tumor progression, particularly the function of the estrogen signal pathway in breast cancer, has been widely discussed. However, the pathogenesis and progression of breast cancer remains unclear. Furthermore, the specific functions of other hormones, including FSH and LH, have not been fully elucidated with regard to the progression of breast cancer. The present study analyzed 187 post-menopausal breast cancer patients to determine whether or not the serum hormonal levels of FSH, LH, $\mathrm{P}$ and PRL were associated with the expression of two key molecular markers, Ki67 and Her-2. Premenopausal patients were excluded as their hormonal levels are affected by their 
physiological cycle and thus their basic hormonal level is difficult to determine in the surgery department of the hospital. The serum FSH levels differed between the Her- $2^{+}$and Her- $2^{-}$patients, and higher FSH levels were identified in the Her- $2^{+}$patients. A higher serum $\mathrm{FSH}$ level was also identified in patients with high Ki67 expression (IHC, 3+). The serum LH level exhibited no significant difference based on Her-2 expression, but a higher serum LH level was observed in the patients with a high $\mathrm{Ki67}$ (IHC, 3+).

FSH and LH belong to a family of glycoprotein hormones, which also include placental hCG and thyroid-stimulating hormone (TSH). FSH and LH are key regulators of reproductive function in the endocrine system and regulate steroidogenesis and gametogenesis in the ovary and the testis. FSH stimulates follicular cell activity through FSHR. FSHR expression is restricted to the sterol cells in the testis and the granulose cells in the ovary $(26,27)$. FSHR expression has been identified in cancer cells. However, the exact function of gonadotropin and its molecular mechanism in the formation and development of tumors has not yet been fully characterized.

The FSH and LH receptors belong to the super family of $\mathrm{G}$ protein-coupled receptors (GPCRs). However, these hormones are unique as they have a large ectodomains that contain a leucine-rich repeat, which is significant for ligand binding. FSHR expression has been identified in various cancer cells, but rarely in breast cancer tissues or cell lines. However, numerous leucine-rich GPCRs (LGRs) have been identified in the human genome (28). In addition to FSHR, other LGR subgroups are able to transmit signals from gonadotropins $(28,29)$. The expression of leucine-containing GPCRs should be detected in breast cancer as FSH is widely distributed in the cytoplasm of epithelial cells in breast cancer, in which higher levels of FSH are observed in benign mammary tumors and breast cancer compared with normal cells (30). Further studies are required to determine whether or not FSH stimulates Her-2 expression and cell proliferation by the LGR subgroup. FSH may function in the malignant transformation of breast cancer via a specific receptor, but not the traditional FSHR.

Furthermore, the menopause affects Her-2 expression in breast cancer (31). One study focused on FSH and Her-2 in breast cancer (32), while certain studies have revealed that FSH stimulates Her-2 expression via specific signaling pathways, including cAMP, in ovarian cancer $(22,33,34)$. In the present study, patients with high Ki67 expression (IHC, 3+) exhibited higher serum FSH and LH levels. A total of $10 \mathrm{ng} / \mathrm{ml} \mathrm{FSH}$ was able to upregulate the expression of Her-2 and Ki67 at the transcriptional level in $24 \mathrm{~h}$ in a breast cancer cell line in vitro (data not shown). Thus, gonadotropins are able to directly or indirectly promote cell proliferation in breast cancer.

To determine whether or not FSH is an independent prognostic marker, the association between FSH or LH and the overall survival (OS) or relapse-free survival (RFS) of the patients was evaluated in the present study. However, the data in this study was acquired from patients who were diagnosed with breast cancer within the past 5 years. Thus, OS/RFS could not be sufficiently evaluated in the study. Future studies with regard to this topic are required.

In conclusion, in the present cases of post-menopausal breast cancer, the Her- $2^{+}$patients were observed to have a higher serum FSH level than the Her-2 ${ }^{-}$patients. The patients with high $\mathrm{Ki} 67$ expression (IHC, $3^{+}$) exhibited higher serum FSH and LH levels. In addition to E2, FSH and LH may have significant functions in breast cancer progression. Thus, further studies are required to determine the exact mechanism at the molecular level.

\section{Acknowledgements}

This study was supported by the National Natural Science Foundation of China (grant nos. 30973465 and 81071879).

\section{References}

1. Siegel R, Naishadham D and Jemal A: Cancer statistics, 2012. CA Cancer J Clin 62: 10-29, 2012.

2. Yang W and Guan L: Bridging the US and China together to conquer cancer: report of the 4th annual meeting of the US Chinese Anti-Cancer Association (USCACA). Chin J Cancer 31: 315-318, 2012.

3. Yang L, Parkin DM, Ferlay J, Li L and Chen Y: Estimates of cancer incidence in China for 2000 and projections for 2005. Cancer Epidemiol Biomarkers Prev 14: 243-250, 2005.

4. Zheng S, Bai JQ, Li J, et al: The pathologic characteristics of breast cancer in China and its shift during 1999-2008: A national-wide multicenter cross-sectional image over 10 years. Int J Cancer 131: 2622-2631, 2012.

5. Slamon DJ, Godolphin W, Jones LA, et al: Studies of the HER-2/neu proto-oncogene in human breast and ovarian cancer. Science 244: 707-712, 1989.

6. Ross JS, Slodkowska EA, Symmans WF, Pusztai L, Ravdin PM and Hortobagyi GN: The HER-2 receptor and breast cancer: ten years of targeted anti-HER-2 therapy and personalized medicine. Oncologist 14: 320-368, 2009.

7. Lopez F, Belloc F, Lacombe F, et al: Modalities of synthesis of Ki67 antigen during the stimulation of lymphocytes. Cytometry 12: 42-49, 1991

8. Goldhirsch A, Wood WC, Coates AS, et al: Strategies for subtypes - dealing with the diversity of breast cancer: highlights of the St. Gallen International Expert Consensus on the Primary Therapy of Early Breast Cancer 2011. Ann Oncol 22: 1736-1747, 2011.

9. Eliassen AH, Tworoger SS and Hankinson SE: Reproductive factors and family history of breast cancer in relation to plasma prolactin levels in premenopausal and postmenopausal women. Int J Cancer 120: 1536-1541, 2007.

10. Tworoger SS and Hankinson SE: Prolactin and breast cancer risk. Cancer Lett 243: 160-169, 2006.

11. Kuijper TM, Ruigrok-Ritstier K, Verhoef-Post M, et al: LH receptor gene expression is essentially absent in breast tumor tissue: implications for treatment. Mol Cell Endocrinol 302: 58-64, 2009.

12. Bodek G, Rahman NA, Zaleska M, et al: A novel approach of targeted ablation of mammary carcinoma cells through luteinizing hormone receptors using Hecate-CGbeta conjugate. Breast Cancer Res Treat 79: 1-10, 2003.

13. Meduri G, Charnaux N, Loosfelt $\mathrm{H}$, et al: Luteinizing hormone/human chorionic gonadotropin receptors in breast cancer. Cancer Res 57: 857-864, 1997.

14. Meduri G, Charnaux N, Spyratos F, Hacene K, Loosfelt H and Milgrom E: Luteinizing hormone receptor status and clinical, pathologic, and prognostic features in patients with breast carcinomas. Cancer 97: 1810-1816, 2003.

15. Caffier $\mathrm{H}$ and Brandau H: Serum tumor markers in metastatic breast cancer and course of disease. Cancer Detect Prev 6: 451-457, 1983.

16. Tsalacopoulos $\mathrm{G}$ and Bloch B: Ectopic production of the beta subunit of human chorionic gonadotrophin by malignant ovarian neoplasms. S Afr Med J 62: 487-488, 1982.

17. Ben-Josef E, Yang SY, Ji TH, et al: Hormone-refractory prostate cancer cells express functional follicle-stimulating hormone receptor (FSHR). J Urol 161: 970-976, 1999.

18. Davies S, Bax CM, Chatzaki E, Chard T and Iles RK: Regulation of endometrial cancer cell growth by luteinizing hormone (LH) and follicle stimulating hormone (FSH). Br J Cancer 83: 1730-1734, 2000 
19. Chen FC, Oskay-Ozcelik G, Bühling KJ, et al: Prognostic value of serum and ascites levels of estradiol, FSH, LH and prolactin in ovarian cancer. Anticancer Res 29: 1575-1578, 2009.

20. WayneCM,Fan HY, Cheng Xand Richards JS: Follicle-stimulating hormone induces multiple signaling cascades: evidence that activation of Rous sarcoma oncogene, RAS, and the epidermal growth factor receptor are critical for granulosa cell differentiation. Mol Endocrinol 21: 1940-1957, 2007.

21. Hunzicker-Dunn M and Maizels ET: FSH signaling pathways in immature granulosa cells that regulate target gene expression: branching out from protein kinase A. Cell Signal 18: 1351-1359, 2006.

22. Choi JH, Choi KC, Auersperg N and Leung PC: Overexpression of follicle-stimulating hormone receptor activates oncogenic pathways in preneoplastic ovarian surface epithelial cells. J Clin Endocrinol Metab 89: 5508-5516, 2004.

23. Huhtaniemi I: Are gonadotrophins tumorigenic - a critical review of clinical and experimental data. Mol Cell Endocrinol 329: 56-61, 2010.

24. Pujol P, Daures JP, Brouillet JP, et al: A prospective prognostic study of the hormonal milieu at the time of surgery in premenopausal breast carcinoma. Cancer 91: 1854-1861, 2001.

25. Zreik TG, Mazloom A, Chen Y, et al: Fertility drugs and the risk of breast cancer: a meta-analysis and review. Breast Cancer Res Treat 124: 13-26, 2010.

26. Sprengel R, Braun T, Nikolics K, Segaloff DL and Seeburg PH: The testicular receptor for follicle stimulating hormone: structure and functional expression of cloned cDNA. Mol Endocrinol 4: 525-530, 1990

27. Kelton CA, Cheng SV, Nugent NP, et al: The cloning of the human follicle stimulating hormone receptor and its expression in COS-7, CHO, and Y-1 cells. Mol Cell Endocrinol 89: 141-151, 1992.
28. Van Loy T, Vandersmissen HP, Van Hiel MB, et al: Comparative genomics of leucine-rich repeats containing $\mathrm{G}$ protein-coupled receptors and their ligands. Gen Comp Endocrinol 155: 14-21, 2008.

29. Hsu SY, Kudo M, Chen T, et al: The three subfamilies of leucine-rich repeat-containing $\mathrm{G}$ protein-coupled receptors (LGR): identification of LGR6 and LGR7 and the signaling mechanism for LGR7. Mol Endocrinol 14: 1257-1271, 2000.

30. Garde SV, Sheth AR, Joseph R, Panchal CJ, Chinoy RF and Sheth NA: Occurrence and de novo biosynthesis of follicle stimulating hormone (FSH) in benign and malignant conditions of human breast. Cancer Lett 75: 1-9, 1993.

31. Wang N, Wang B, Wang Y and Hu J: Estrogen receptor positive operable breast cancer: does menopausal status impact on HER2 and progesterone receptor status? Breast 20: 519-524, 2011.

32. Hernández L, Nuñez-Villarl MJ, Martínez-Arribas F, Pollán M and Schneider J: Circulating hormone levels in breast cancer patients. Correlation with serum tumor markers and the clinical and biological features of the tumors. Anticancer Res 25: 451-454, 2005 .

33. Choi JH, Chen CL, Poon SL, Wang HS and Leung PC: Gonadotropin-stimulated epidermal growth factor receptor expression in human ovarian surface epithelial cells: involvement of cyclic AMP-dependent exchange protein activated by cAMP pathway. Endocr Relat Cancer 16: 179-188, 2009.

34. Zhang Z, Jia L, Feng Y and Zheng W: Overexpression of folliclestimulating hormone receptor facilitates the development of ovarian epithelial cancer. Cancer Lett 278: 56-64, 2009. 